cent. of all skin diseases respond so promptly to mercury or iodid of potash? Why do many scrofulous and weakly children come from syphilitics?

The way of the syphilitic microbe heretofore has been past finding out. Its effects depend much upon the soil in which it operates, the number operating and the power of the leucocytes to prevent their ruth. less ravages. I believe a blonde suffers with syphilis more than a brunette. I have never seen a syphilitic microbe (but it has been claimed recently that it has been discovered by Van Niesen), and it is doubtful if anyone else has seen one. We know little of its history, how it acts, or how long it remains in the system. We do know its deleterious effect on humanity when it once gains admission into the blood. The microbe of many other germ diseases, such as scarlet fever, measles, etc., does its work quickly, either to the death of the patient attacked by it or to the surrender to the generalship of the mighty host of leucocytes. After convalescence, in many of these cases, there seems to be no trace of the microbe remaining. It is not so with the syphilitic microbe. Its effects on an individual can be seen many years after its first inception and in his posterity.

It may be admitted that the type of syphilis of the present is of a milder form than formerly. If so, it is because the people have been either directly or hereditarily well syphilized. Still, there are yet different types of the disease, or evidences of its acting differently on different constitutions. I have seen and treated cases where, as yet, the effect of the disease has been controlled or lies dormant, for there have been no traces of the disease either in the children or parents. Yet in other families I have observed traces of it still existing both in the parents and in their children. have never treated a case of syphilis in which the vitality of the person so affected was not lowered, and it is doubtful whether there has been a case in whioh the person so affected did not have to take a retrogressive step to a lower plane of development, intel. lectually, morally and physically, and it is probable that such a person would never rise to a plane he occupied before being inoculated. Just what time the syphilitic microbe departs from the body, or the form it assumes in injuring the constitution many years after the inception of the disorder, has not been indicated. Is not the disease, after it enters the blood, liable at any time during the lifetime of the patient to break out like a voloano? What condition of the blood causes diseases of the mucous membranes and the nervous system many years after the original disease? These are pertinent questions, and questions that must be answered before we can make such sweeping assertions "that a patient may be rotten with the effects of the disease and yet no harm come from it," for the microbe has departed "and there is no danger of imparting it to others." What made the patient rotten? Does not a patient recover when the cause is removed? This has been my education by experience, which is the best teacher.

Again, will not these conditions of the blood in tertiary syphilis, which cause such destructive constitutional changes to take place, if transfused to a non-syphilitic, produce the same destructive conditions in him? Is not the offspring of a parent or parents a very good register of the health of the parent or parents? Could we expect to breed a strong people from syphilitics? When the gonococci may linger for so many years in the genito-urinary tract, is it more reasonable to expect the syphilitio microbe, which has a much more extended territory in which to exist, will relinquish its possession sooner? Why is it that syphilitic women are constantly syphilizing men who copulate with them, and vice versa?

Fifth Avenue and Ross Street.

\section{PLEURITIS GONORRHOICA.}

\author{
REPORT OF A CASE.
}

BY J. RUDIS JICINSKY, A.M., M.D.

$$
\text { CEDAR RAPIDS, IOWA. }
$$

In discussing the question of the causes of secondary pleuritis, and especially of the connection existing between gonococcus (Neisser) and the diseases of the lungs, heart, joints, conjunctiva and serous membranes, ${ }^{1}$ it is not my intention to review the work of a large number of observers who have written on the subject during the last few years. It is not even my intention to add anything new on this subject, and, without forgetting the observations of many who have worked in this field, I will simply confine my remarks to what I have observed myself in an especially interesting case. Our text-books say that secondary pleuritis occurs during an attack of pneumonia, pericarditis, rheumatism, variola, scarlatina, Bright's disease, or malarial fever, and chronic pleurisy follows an attack, or is the result of tuberculosis, Bright's disease, or alcoholism. Pleurisy is almost invariably excited by certain micro-organisms, which find access to the pleural membrane. (Lyman.) In our case it was gonococcus attacking the membrane.

Case 1.-Chas. P., male, aged 24, was sent to me for X-ray diagnosis of the chest, by one of my colleagues, who suspected pleurisy as the result of tuberculosis. The disease began with a chill, followed by lancinating pains near the nipple and in the axilla, on the left side, aggravated by coughing and breathing, associated with slight tenderness on pressure. Respiration was rapid and shallow -40 to 42 per minute. There was a shart, dry, hacking cough in the beginning, later on harassing, with copious sputum, night sweats and fever; loss of weight; pulse compressible but frequent, ranging between 110 and 120 beats per minute. When dyspnea became aggra. vated and the cough more distressing, with the carciac action embarrassed, the countenance wearing once an anxious expression, the aspirator was used, but with a negative result. In. spection : deficient movement of the left side. Palpation : feeble fremitus. Percussion: dulness. Auscultation : vesicular murmur associated with a grazing friction sound. Family history good. Such was the record given to me.

Patient being exposed to the X-ray, took all his clothes off. The apparatus was connected and the switch closed. The current passing through the aluminium plate in the tube gave the green light, while the X-ray was observed with the fluoroscope. In the next moment, when the fluoroscope was laid aside, I happened to look down on the generative organs of our patient, which in the dark room, under the effect of the green light, looked somewhat suspicious, Examination was made and swelling found, outlined at the back of the scrotum and considerable in extent, and also tenderness. On questioning patient he first denied ever having had venereal disease, then said that he had "slight" discharge from the lips of the reddened meatus many months ago. This stopped without treat. ment, but now the swelling came on, characterized sometimes by pain passing along the cord to the loins. The characteristic symptoms rendered the diagnosis easy, proving only the essential requirement of complete, most careful and thorough examinations of all our patients, which in this case was nearly overlooked. At that moment I never thought that this condition bad anything to do with the disease of the lungs.

As to the X-ray examination of the lungs of our patient, it was demonstrated again that in the Roentgen rays and fluoroscope we possessed accurate means for diagnosticating changes of lung tissue. They were used in this case, as in other experiments of mine, as factors corroborative of results arrived at

1 Rheumatismus Gonorrhoicus, Endocarditis Gonorrhoica, Pleuritis, Gonorrhoica, etc. "Specielni Pathologie a Therapie Vnitrnich Nemoci." 
by auscultation and percussion, enabling us to recognize more fully and accurately the degree, position and relation of areas diseased. In our case there were no spots of isolated foci over the lungs, no haziness indicating tuberculous infiltration, no decided shadows of consolidation and no circumscribed spots of bright reflex, surrounded by dark rings, which would point to cavities, but there was darkness on the left at the lower portion of the lungs, indicating pleuritic thickenings. Numerous microscopic examinations of the sputum ehowed no "bacilli tuberculosi," but micrococci gonorrheæ or gonococci (Neisser) in great numbers.

Various theories are offered to explain this condition in secondary pleuritis and its relation to gonorrheal infection, but none of them have yet proved satisfactory. In some cases there seems to be no doubt that the gonococci are carried through the blood and lymphatics to the pleura, finding there, as in this case, a locus resistantice minoris, for although these micro-organisms have not been discovered in the blood, they have been found in the sputum, and their identity has been fairly well established, as in our case, through their behavior with stains, and through culture experiments on human blood serum, where they gave semblance of a growth, the temperature being between 33 and 37 degrees $C$. In three days we had a very thin, almost invisible, moist yellowish growth, seeming to be composed of little drops. Under low power, characteristic small processes shooting out from the smooth border were seen. Transferred to fresh media they gave same results. ${ }^{2}$

The patient, being a traveler, was confined to bed immediately, the epididymitis treated with elevation of scrotum and application of evaporating lotions. When acute inflammatory symptoms subsided, the testicle was strapped and patient finaliy allowed to go to California for substantial rest. All other symptoms of pleurisy under treatment were much bet ter, patient improving. The pleuritic process terminated in eight weeks, patient being convalescent from that disease. Râles were still present, but were higher pitched, and percussion note was far from satisfactory. I would not have been surprised at some other complication, but then another curious feature manifested itself; the discharge from the meatus of the penis returned and continued for several weeks - or at least it was so reported to me-showing that gonorrhea in our case was not only a chronic, specific and infectious disease, with local manifestations, but with a marked systemic reaction.

Hyde, speaking of such cases, says that they seem to be essentially pyemic, and to be due to infection with pus coccus, which gains admittance to the circulation through the urethral or other epithelium that has been damaged or destroyed by the gonococci. Andere, describing the etiology of endocarditis, states: "Acute endocarditis may be of gonorrheal origin. In the inflammatory products of this condition, Hering found the gonococci, as has also Councilman, in the heart muscles. As the result of invasion of the blood by the gonococci, suppurative arthritis may also be occasioned, and now the olinical picture is that of general septico-pyemia. I observed one case in which pleurisy was associated, and among the numerous widespread complications, iritis deserves special mention."

Dr. Aug. Fisher, Chicago, refers in Ces. Lekarske Listy, 1898, to a similar "Case of Secondary Pleuritis as a Result of Chronic Gonorrhea."

A man, aged 26, single, machinist, vigorous, family history good, had gonorrhea four years ago; was never sick before. In March he gave all the characteristic symptoms of pleurisy Two weeks later aspiration was made, with no result. He had occasionally slight discharge from the meatus, as finally admitted, but these stopped during the present disease, which in the third week was marked by increased cough, followed by copious purulent expectoration. Microscopic examination of the sputum revealed a large number of gonococci (Neisser), but no bacilli tuberculoei. In October, when the symptoms of pleurisy subsided, and the patient was feeling well, the dis charge from the meatus showed itself again, and the case was referred to a specialist.

I have to say again that my interest in our case arose altogether independently of any intention to investigate the etiology of secondary pleurisy, as

2 Tonton: Der gonococcus und seine Beziehungen zu gonorrhoischen Processen, Berliner klin. Woch., No. 21. 1894. Venereal Diseases: Prof.
Dr. Franz Mracek. regards gonococcus. It was only by accident during the study of the X-ray diagnosis in the diseases of the lungs, that I was led to consider the possibility of a relation of an irritant called "gonococcus"-what is in the name?-or an irritant called "bacillus tuber. culosis;" both are and remain to be irritants if finding a soil in the lungs. This subject presented itself to me, as it seems to have presented itself to the minds of others. From the beginning it seemed evident that in investigating this question one was bound to follow the rules usually followed in bacteriologic investigations, but the end, from a pathologic standpoint, remains the same, just as well as the problem, how and through what channels the gonococci went up to the pleura and, irritating the same, caused hyperemia, exudation and then resolution. Malsbury makes a good point in this direction, saying: "The organisms, unless arrested, are prone to multiply, to spread into new territory and transmit their toxic products to the general circulation." If we had had in our case bacilli tuberculosi, the mode of infection could be explained through the respiratory organs, etc., but with gonococci we seem to be at sea.

In reporting the case, I fully realize that one or two cases are very little to build on, but it shows that nature sometimes adapts itself to newly arising circumstances, even at the expense of science, bringing our terms "inflammation" and "infection" very close together.

\section{THE FUNCTION OF BRÜCKE'S MUSCLE.}

BY DR. V. FUKALA, WIEN.

Translated by J. W. Sherer, M.D., Kansas City, Mo., from Arch. f. Augenheilk., Bd. xxxvi, p. 65.

In 1864 Brücke published his views in regard to what he calls the "ciliary muscle." As is well known, this muscle consists of two parts, one circular, and one longitudinal. The circular portion escaped his observation, but he correctly apprehended the longitudinal part, and to it his name has been applied. Brücke first demonstrated that the ciliary muscle was unstriated. It had hitherto been designated the "ligamentum scleroticum," "plexus ciliaris," or "ganglion ciliure," according to the different views of its structure. Brücke failed to correctly understand the function of the longitudinal muscle, and this error, to a degree, still prevails. In his "Anatomic Description of the Human Eyeball" he states: "the muscle discovered by me extends from the corneo-scleral junction to the roots of the ciliary process." Unfortunately he did not follow the muscle farther into the choroid, and consequently there escaped him the important fact that it extends nearly to the posterior ocular pole. Brücke's conception that the muscle had the function of drawing the choroid anteriorly is erroneous. He expressed himself regarding this as follows: "This muscle draws the choroid tightly to the retina and vitreous, and reduces the closed space formed by the cornea, choroid and itself. At the same time it draws forward the zonula Zinnii, which is united with the ciliary processes, reducing the tension between the lens and ciliary processes. Whether this causes a forward movement of the lens can not be stated, since we do not know how far such movement. would be permitted by the aqueous." Brücke appeared inclined to bring the action of his muscle in

3 Gonorrhea in Male; Journal Am. Med. Assn., July 16, 1898. 